\title{
Diagnóstico da formação especializada em enfermagem pediátrica e neonatal no Brasil
}

Diagnosis of specialized training in pediatric and neonatal nursing in Brazil

Diagnóstico de formación especializada en enfermería pediátrica y neonatal en Brasil

Julia Reis Conterno ${ }^{1}$ (D) https://orcid.org/0000-0002-4642-1420

Beatriz Rosana Gonçalves de Oliveira Tos0 ${ }^{1}$ (D) https://orcid.org/0000-0001-7366-077X

Elisa da Conceição Rodrigues ${ }^{2}$ (D) https://orcid.org/0000-0001-6131-8272

Myriam Aparecida Mandetta ${ }^{3}$ (D) https://orcid.org/0000-0003-4399-2479

\section{Resumo}

Objetivo: Diagnosticar a oferta de cursos de especialização em enfermagem pediátrica e neonatal nas Instituições de Ensino Superior (IES) brasileiras.

Métodos Estudo quantitativo, descritivo abrangendo instituições de ensino superior com curso de graduação em Enfermagem, cadastradas no site e-MEC. Dados secundários, coletados a partir dos relatórios gerados na página mencionada. Foram organizados, digitados em tabelas, para análise estatística descritiva.

Resultados: A maioria dos cursos ofertados é na modalidade especialização (96,23\%), concentrados na Região Sudeste (29,56\%), ofertados por instituições privadas $(96,77 \%)$, com predomínio de especialização em enfermagem pediátrica e neonatal associados $(28,49 \%)$, presenciais $(95,69 \%)$, carga horária média entre 400 a 499 horas $(34,63 \%)$, oferta média de 81 a 100 vagas $(28,49 \%)$.

Conclusão: Há necessidade de expansão dessa formação para as demais regiões do país, assim como 0 aumento na oferta de residências de enfermagem na área.

\section{Abstract}

Objective: To diagnose the specialization courses offer in pediatric and neonatal nursing, in Brazilian Under Graduation Institutions.

Methods: Quantitative, descriptive study covering under graduation institutions with undergraduate nursing courses registered on the e-MEC website. The data were secondary, collected from the reports generated on the mentioned webpage. They were organized, typed in tables, for descriptive statistical analysis.

Results: Most of the courses offered are in the specialization modality (96.23\%), concentrated in the Southeast Region $(29.56 \%)$, offered by private institutions $(96.77 \%)$, with a predominance of specialization in pediatric and neonatal nursing associated (28.49\%), presential classes (95.69\%), average study time between 400 to 499 hours (34.63\%), average vacancies of 81 to $100(28.49 \%)$.

Conclusion: There is a need to expand this training to other regions of the country, as well as the increase in the supply of nursing residence courses in this field.

\section{Resumen}

Objetivo: Diagnosticar la oferta de cursos de especialización en enfermería pediátrica y neonatal en Instituciones de Educación Superior (IES) de Brasil.

Métodos Estudio cuantitativo y descriptivo que abarca instituciones de educación superior con cursos de pregrado en enfermería, registrado en el sitio web de e-MEC. Datos secundarios, recopilados de los informes generados en la página mencionada. Se organizaron, mecanografiados en tablas, para el análisis estadístico descriptivo.

Resultados: La mayoría de los cursos ofrecidos se encuentran en la modalidad de especialización (96.23\%), concentrados en la Región Sudeste (29.56\%), ofrecidos por instituciones privadas (96.77\%), con predominio de la especialización en enfermería pediátrica y neonatal asociada (28.49\%), presencial (95.69\%), carga de estudio promedio entre 400 y 499 horas (34.63\%), oferta promedio de 81 a 100 vacantes (28.49\%).

Conclusión: Existe la necesidad de ampliar esta capacitación a otras regiones del país, así como el aumento de la oferta de cursos de residencia en enfermería en el área de estudio.

\section{Descritores}

Enfermagem neonatal; Enfermagem pediátrica; Capacitação profissional; Capacitação de recursos humanos em saúde

\section{Keywords}

Neonatal nursing; Pediatric nursing; Professional training; Health human resource training

\section{Descriptores}

Enfermería neonatal; Enfermería pediátrica; Capacitación profesional; Capacitación de recursos humanos en salud

\section{Como citar:}

Conterno JR, Toso BR, Rodrigues EC, Mandetta MA. [Diagnosis of specialized training in pediatric and neonatal nursing in Brazil]. Rev Soc Bras Enferm Ped. 2019;19(2):97-110. Portuguese 


\section{Introdução}

No Brasil, o Ministério da Saúde, instituiu a Política Nacional de Atenção Integral à Saúde da Criança (PNAISC) no âmbito do Sistema Único de Saúde (SUS), com o objetivo de promover e proteger a saúde da criança, com atenção para as que apresentam situação de vulnerabilidade, articulando os serviços de saúde, por meio de sete eixos estratégicos, dentre eles, o acompanhamento integral do seu crescimento e desenvolvimento. ${ }^{(1)}$

Essa política é relevante para a saúde da criança considerando que a evolução do processo de crescimento e desenvolvimento ocorre com maior velocidade nos primeiros anos de vida. Nesse sentido, a vigilância desse processo por parte de profissionais de saúde habilitados é de extrema importância.

Como membro da equipe multidisciplinar, o enfermeiro exerce um papel central no seguimento da criança, por meio de uma prática de enfermagem eficiente, possibilitando a vigilância do crescimento e do desenvolvimento nesse período, cuja relevância reside em reduzir o número de agravos, proporcionar boa qualidade de vida e favorecer seu pleno crescimento e desenvolvimento. ${ }^{(2)}$

Dessa maneira, torna-se fundamental o investimento na formação de recursos humanos na área da saúde, para dar conta da atenção a esse grupo populacional, o que inclui a abrangência de atividades lúdicas no cuidado e a inserção da família, principalmente no ambiente hospitalar, carecendo profissionais preparados para o cuidado a essa faixa etária, atuando em equipe multidisciplinar, na qual os enfermeiros e preferencialmente os enfermeiros especialistas em pediatria e neonatologia participam. Nesse sentido, o olhar para a formação especializada está inexoravelmente intrincado com a formação na graduação, ambos abordados nesse estudo.

Observa-se que a formação do enfermeiro no Brasil no nível de graduação, em escolas públicas e privadas, tem passado por uma expansão acelerada do sistema, com aumento na oferta de cursos, crescimento das matrículas no setor privado e da racionalização de recursos nas instituições públicas de ensino superior. Contudo, essa realidade expansionista nem sempre vem acompanhada da qualidade necessária que o setor saúde requer. Observa-se a necessidade de comprometimento na formação de sujeitos críticos e reflexivos no atendimento à saúde integral do ser humano, bem como na aquisição de competências e habilidades profissionais de saúde/enfermagem, para conhecer e intervir sobre os problemas/situações de saúde-doença mais prevalentes no perfil epidemiológico nacional, conforme explicitado nas atuais Diretrizes Curriculares Nacionais do Curso de Graduação em Enfermagem..$^{(3-5)}$

Entretanto, a mais de uma década estudiosos apontam a necessidade de ampliar o quantitativo de enfermeiros, para atender as múltiplas e diversas demandas de atenção à saúde da população nos níveis locais, regionais e nacionais. ${ }^{(6)}$ A proporção atual de enfermeiros no país segundo a pesquisa Cofen em 2016 é de 0,75/500 habitantes, não está de acordo com o recomendado pela Organização Mundial da Saúde (OMS), cujo número ideal de profissionais de enfermagem em proporção à população é de um para cada 500 habitantes. ${ }^{(7)}$

Cadastrados no Ministério da Educação (MEC) no ano de 2017, encontravam-se 1098 cursos de graduação em Enfermagem, enquanto em 2019 esse número aumentou para 1289, um crescimento de $14,8 \%$ ou 191 novos cursos em dois anos. Os dados do MEC demonstram a expansão dos cursos de Enfermagem no Brasil, com um cadastro de $76 \%$ das escolas presencias em 2017, aumentando para 89,9\% em 2019 e o ensino a distância, de $11 \%$ em 2017, diminuindo para $10 \%$ em 2019. A minoria das escolas públicas e gratuitas (13\% em 2017) reduziu ainda mais em 2019, para 11,4\%, estando o ensino de Enfermagem na graduação concentrado nas instituições privadas (94,4\%). Ainda, $7,6 \%$ dos cursos estão aprovados, mas não iniciaram as atividades e 2,4\% foram extintos ou estão em processo de extinção. Demonstra-se a concentração do número de escolas na região Sudeste (31,8\% em 2017; 41,4\% em 2019), seguida do Nordeste (23,1\% em 2017; $28,1 \%$ em 2019), acompanhando a densidade demográfica dessas duas regiões. A região Norte, com menor número de cursos (9,1\% em 2017; 9,6\% em 2019) também concentra o maior número de cursos de graduação em Enfermagem à distância (23.4\%).

Essas características podem ser percebidas na distribuição dos cursos de graduação em Enfermagem, conforme tabela $1 .^{(8)}$

A Sociedade Brasileira de Enfermeiros Pediatras SOBEP congrega enfermeiros especialistas no cuidado 
Tabela 1. Distribuição de cursos de graduação em Enfermagem por estado da federação, de acordo com a forma de oferta e gratuidade

\begin{tabular}{|c|c|c|c|c|c|c|c|c|c|c|c|}
\hline \multirow[t]{2}{*}{ Estado } & \multicolumn{2}{|c|}{$\begin{array}{c}\mathrm{N}^{0} \text { Instituições } \\
\mathrm{n}(\%)\end{array}$} & \multicolumn{2}{|c|}{$\begin{array}{c}\text { Presencial } \\
\mathrm{n}(\%)\end{array}$} & \multicolumn{2}{|c|}{$\begin{array}{c}\text { Distância } \\
\text { n(\%) }\end{array}$} & \multicolumn{2}{|c|}{$\begin{array}{c}\text { Pública } \\
\text { n(\%) }\end{array}$} & \multirow{2}{*}{$\begin{array}{c}\begin{array}{c}\text { Privada } \\
\text { n(\%) }\end{array} \\
2019\end{array}$} & \multirow{2}{*}{$\begin{array}{c}\text { Não } \\
\text { Iniciado } \\
\text { n(\%) } \\
2019\end{array}$} & \multirow{2}{*}{$\begin{array}{c}\text { Curso } \\
\text { Extinto } \\
2019\end{array}$} \\
\hline & 2017 & 2019 & 2017 & 2019 & 2017 & 2019 & 2017 & 2019 & & & \\
\hline Brasil & 1098 & 1289 & $\begin{array}{c}834 \\
(76 \%)\end{array}$ & $\begin{array}{c}1159 \\
(89,9 \%)\end{array}$ & $\begin{array}{c}125 \\
(11 \%)\end{array}$ & $\begin{array}{c}130 \\
(10,0 \%)\end{array}$ & $\begin{array}{c}143 \\
(13 \%)\end{array}$ & $\begin{array}{c}147 \\
(11,4 \%)\end{array}$ & $\begin{array}{c}1218 \\
(94,4 \%)\end{array}$ & $\begin{array}{c}98 \\
(7,6 \%)\end{array}$ & $\begin{array}{c}32 \\
(2,4 \%)\end{array}$ \\
\hline Região Sul & $\begin{array}{c}134 \\
(12,2 \%)\end{array}$ & $\begin{array}{c}190 \\
(13,9 \%)\end{array}$ & $\begin{array}{c}120 \\
(89,5)\end{array}$ & $\begin{array}{c}174 \\
(91,5 \%)\end{array}$ & $\begin{array}{c}15 \\
(11,1 \%\end{array}$ & $\begin{array}{c}16 \\
(8,4 \%)\end{array}$ & $\begin{array}{c}20 \\
(14,9 \%)\end{array}$ & $\begin{array}{c}21 \\
(11,0 \%)\end{array}$ & $\begin{array}{c}169 \\
(88,9 \%)\end{array}$ & $\begin{array}{c}11 \\
(5,7 \%)\end{array}$ & $\begin{array}{c}12 \\
(6,3 \%)\end{array}$ \\
\hline Rio Grande do Sul & 44 & 63 & 39 & 57 & 5 & 6 & 7 & 7 & 56 & 1 & 2 \\
\hline Santa Catarina & 32 & 47 & 28 & 44 & 4 & 3 & 3 & 4 & 43 & 3 & 2 \\
\hline Paraná & 58 & 80 & 53 & 73 & 6 & 7 & 10 & 10 & 70 & 7 & 8 \\
\hline Região sudeste & $\begin{array}{c}350 \\
(31,8 \%)\end{array}$ & $\begin{array}{c}534 \\
(41,4 \%)\end{array}$ & $\begin{array}{c}331 \\
(94,5 \%)\end{array}$ & $\begin{array}{c}510 \\
(95,5 \%)\end{array}$ & $\begin{array}{c}25 \\
(7,1 \%)\end{array}$ & $\begin{array}{c}24 \\
(4,5 \%)\end{array}$ & $\begin{array}{c}28 \\
(8,0 \%)\end{array}$ & $\begin{array}{c}30 \\
(5,6 \%)\end{array}$ & $\begin{array}{c}504 \\
(94,4 \%)\end{array}$ & $\begin{array}{c}40 \\
(7,5 \%)\end{array}$ & $\begin{array}{c}20 \\
(3,7 \%)\end{array}$ \\
\hline São Paulo & 161 & 241 & 158 & 234 & 6 & 7 & 9 & 11 & 230 & 23 & 10 \\
\hline Rio de Janeiro & 46 & 106 & 41 & 99 & 7 & 7 & 6 & 6 & 100 & 5 & 10 \\
\hline Espirito Santos & 23 & 30 & 18 & 26 & 5 & 4 & 2 & 2 & 28 & 5 & -- \\
\hline Minas Gerais & 120 & 157 & 114 & 151 & 7 & 6 & 11 & 11 & 146 & 7 & -- \\
\hline Região Centro-Oeste & $\begin{array}{c}108 \\
(9,8 \%)\end{array}$ & $\begin{array}{c}153 \\
(11,8 \%)\end{array}$ & $\begin{array}{c}91 \\
(84,2 \%)\end{array}$ & $\begin{array}{c}131 \\
(85,6 \%)\end{array}$ & $\begin{array}{c}20 \\
(18,5 \%)\end{array}$ & $\begin{array}{c}22 \\
(14.3 \%)\end{array}$ & $\begin{array}{c}19 \\
(17,5 \%)\end{array}$ & $\begin{array}{c}18 \\
(11,7 \%)\end{array}$ & $\begin{array}{c}135 \\
(88,2 \%)\end{array}$ & $\begin{array}{c}8 \\
(5,2 \%)\end{array}$ & $\begin{array}{c}3 \\
(1,9 \%)\end{array}$ \\
\hline Mato Grosso do Sul & 19 & 26 & 15 & 20 & 5 & 6 & 4 & 4 & 22 & 1 & -- \\
\hline Goiás & 19 & 50 & 15 & 44 & 5 & 6 & 5 & 4 & 46 & -- & 3 \\
\hline Distrito Federal & 43 & 41 & 39 & 35 & 5 & 6 & 3 & 3 & 38 & 4 & -- \\
\hline Mato Grosso & 27 & 36 & 22 & 32 & 5 & 4 & 7 & 7 & 29 & 3 & -- \\
\hline Região Nordeste & $\begin{array}{c}254 \\
(23,1 \%)\end{array}$ & $\begin{array}{c}362 \\
(28,1 \%)\end{array}$ & $\begin{array}{c}217 \\
(85,4 \%)\end{array}$ & $\begin{array}{c}323 \\
(89,2 \%)\end{array}$ & $\begin{array}{c}39 \\
(15,3 \%)\end{array}$ & $\begin{array}{c}39 \\
(10,7 \%)\end{array}$ & $\begin{array}{c}59 \\
(23,2 \%)\end{array}$ & $\begin{array}{c}59 \\
(16,2 \%)\end{array}$ & $\begin{array}{c}303 \\
(83,7 \%)\end{array}$ & $\begin{array}{c}35 \\
(9,6 \%)\end{array}$ & $\begin{array}{c}2 \\
(0,5)\end{array}$ \\
\hline Bahia & 69 & 89 & 65 & 84 & 4 & 5 & 9 & 9 & 80 & 10 & -- \\
\hline Sergipe & 12 & 21 & 8 & 17 & 4 & 4 & 2 & 2 & 19 & 2 & -- \\
\hline Alagoas & 18 & 23 & 13 & 19 & 5 & 4 & 2 & 3 & 20 & 2 & -- \\
\hline Paraíba & 23 & 27 & 19 & 23 & 4 & 4 & 5 & 5 & 22 & -- & -- \\
\hline Pernambuco & 40 & 64 & 36 & 60 & 5 & 4 & 8 & 6 & 58 & 9 & 1 \\
\hline Rio Grande do Norte & 16 & 27 & 12 & 22 & 5 & 5 & 6 & 6 & 21 & 3 & 1 \\
\hline Ceará & 32 & 51 & 28 & 46 & 4 & 5 & 6 & 6 & 45 & 7 & -- \\
\hline Piauí & 22 & 30 & 18 & 27 & 4 & 3 & 7 & 7 & 23 & 1 & -- \\
\hline Maranhão & 22 & 30 & 18 & 25 & 4 & 5 & 14 & 15 & 15 & 1 & -- \\
\hline Região Norte & $\begin{array}{c}100 \\
(9,1 \%)\end{array}$ & $\begin{array}{c}124 \\
(9,6 \%)\end{array}$ & $\begin{array}{c}75 \\
(75,0 \%)\end{array}$ & $\begin{array}{c}94 \\
(75,8 \%)\end{array}$ & $\begin{array}{c}26 \\
(26,0 \%)\end{array}$ & $\begin{array}{c}29 \\
(23,4 \%)\end{array}$ & $\begin{array}{c}17 \\
(17,0 \%)\end{array}$ & $\begin{array}{c}17 \\
(13,7 \%)\end{array}$ & $\begin{array}{c}107 \\
(86,2 \%)\end{array}$ & $\begin{array}{c}5 \\
(4,0 \%)\end{array}$ & $\begin{array}{c}5 \\
(4,0 \%)\end{array}$ \\
\hline Amapá & 7 & 9 & 4 & 7 & 3 & 2 & 2 & 2 & 7 & 2 & -- \\
\hline Pará & 26 & 38 & 23 & 32 & 3 & 6 & 5 & 4 & 34 & 1 & -- \\
\hline Roraima & 7 & 7 & 4 & 5 & 3 & 2 & 2 & 2 & 5 & 1 & -- \\
\hline Amazonas & 14 & 17 & 10 & 13 & 5 & 4 & 4 & 4 & 13 & -- & -- \\
\hline Rondônia & 20 & 23 & 17 & 17 & 3 & 5 & 1 & 1 & 22 & 1 & -- \\
\hline Acre & 7 & 8 & 3 & 4 & 4 & 4 & 2 & 2 & 6 & -- & -- \\
\hline Tocantins & 19 & 22 & 14 & 16 & 5 & 6 & 1 & 2 & 20 & -- & 5 \\
\hline
\end{tabular}

Nota: As diferenças numéricas dizem respeito a distintas origens dos dados na base de dados do MEC.

Fonte: Ministério da Educação [Internet]. e-MEC. 2017 [cited 2017 Mar 10]. Available from: http://portal.mec.gov.br/e-mec-sp-257584288. ${ }^{(8)}$

a saúde da criança, definida como ser em crescimento e desenvolvimento do nascimento até o final da adolescência, e que precisa ser atendida nesse processo por profissional com competência para promover o melhor cuidado e otimizar suas potencialidades. ${ }^{(9)}$ Desde sua criação há 23 anos, outorgou o Título de Especialista em Enfermagem Pediátrica a 25 profissionais e de Enfermagem Neonatal a 10 profissionais, que se submeteram ao exame de titulação realizado por ocasião dos congressos da entidade. No entanto, após todos esses anos, observa-se pouca procura para a realização do exame pelos enfermeiros que concluem cursos de especialização ou que atuam na área já a algum tempo, e um número expressivo de reprovações, revelando uma defasagem na formação do especialista.

A SOBEP preocupada com a qualidade e quantidade de profissionais no mercado de trabalho e a emergência de cursos de especialização disponíveis iniciou um estudo para estabelecer as competências mínimas desse profissional, e oferecer às entidades 
formadoras uma diretriz curricular que as englobem. Como uma etapa desse estudo, entende-se que é preciso conhecer a realidade da formação do especialista no Brasil. Dessa maneira, partindo do mapeamento das instituições formadoras, espera-se obter as informações sobre a oferta de pós-graduação lato-sensu na área de enfermagem e mais especificamente na enfermagem pediátrica e neonatológica. Parte-se do pressuposto de que a integração da pós-graduação com a graduação na área da Enfermagem influencia substancialmente a qualidade da formação profissional, o que leva a necessidade desta investigação, que tem como objeto de estudo a construção do conhecimento sobre formação especializada na área da enfermagem pediátrica. Em face do exposto, questiona-se: Como ocorre a formação do enfermeiro pediatra na pós-graduação lato sensu nas instituições de ensino nacionais?

Diagnosticar a oferta de cursos de especialização em enfermagem pediátrica e neonatológica nas Instituições de Ensino Superior (IES) brasileiras.

\section{Métodos}

Estudo quantitativo, descritivo, transversal, com abrangência nacional, uma vez que se identificou os cursos de pós-graduação lato sensu na área, em instituições públicas e/ou privadas, no banco de dados do e-MEC, cadastrados e ativos na plataforma de dados desse órgão governamental. A coleta ocorreu nos períodos de agosto e setembro de 2017 e em agosto de 2019 os dados foram obtidos novamente para sua atualização e comparação em relação aos dois períodos. A partir desse banco de dados, cujos projetos estão disponíveis online e são documentos de acesso público, obtiveram-se as informações desejadas sobre os cursos de formação na área do estudo, agrupados em instrumento de coleta desenhado para o estudo, contendo as variáveis: instituição de ensino superior, curso de graduação, curso de especialização, unidade federativa, categoria administrativa, organização acadêmica, tipo de credenciamento e situação.

Para identificação dos cursos foram utilizadas as palavras chave: enfermagem pediátrica e/ou em pediatria; enfermagem neonatal e/ou em neonatologia; terapia intensiva neonatal; terapia intensiva pediátrica; saúde da criança; saúde do adolescente; enferma- gem obstétrica. Todas as palavras chaves foram cruzadas entre si. A busca ocorreu ao mesmo tempo por duas pesquisadoras e os resultados obtidos no banco de dados foram cruzados entre si, completando-se os dados faltantes em cada busca e excluindo-se os repetidos, até a obtenção do total de cursos.

Todos os cursos de especialização nas áreas mencionadas que estavam ativos na plataforma online do e-MEC e acessíveis na íntegra para avaliação foram incluídos. Os dados foram agrupados e a análise foi efetuada por meio de estatística descritiva, com números absolutos e relativos, apresentados em gráficos e tabelas. Em função de analisar dados secundários, públicos e disponíveis online, o estudo dispensou análise por comitê de ética em pesquisa.

\section{Resultados}

Identificaram-se 186 cursos em 2017 e 178 em 2019 cadastrados na plataforma e-MEC. A maioria está concentrada na região Sudeste (38,7\% em 2017; 37,6\% em 2019), seguido da região Nordeste (25,8\% em 2017; $29,7 \%$ em 2019). Houve pouca variação no período de dois anos, com ligeiro decréscimo na oferta de cursos $(4,4 \%)$. A distribuição dos cursos de acordo com o Estado da federação, comparando-se os anos de 2017 e 2019, está apresentada na tabela 2. ${ }^{(8)}$

A comparação do número de cursos de graduação e respectiva oferta de pós-graduação lato sensu nas regiões está demonstrada na figura $1{ }^{(8)} \mathrm{O}$ crescimento da graduação não foi acompanhado pelo crescimento na pós-graduação. Percebe-se uma diferença expressiva entre o número de oferta de cursos de graduação em relação a existência de cursos de pós-graduação lato-sensu na área pediátrica e neonatal.

Quanto as especificidades de cada curso por unidade da federação, relacionadas a ser presencial ou a distância, a carga horária, ao número de vagas ofertadas, a modalidade de oferta - especialização ou residência, a área de oferta - pediatria, neonatologia, terapia intensiva, associado a outros áreas, como a obstetrícia, por exemplo, estão apresentados nos quadros 1,2 e 3 .

Quanto as especificidades dos cursos de especialização ativos no e-MEC em 2019, em Enfermagem Neonatal e/ou Neonatologia foram 17 (9,1\%), em En- 
Tabela 2. Distribuição de cursos de especialização por estados brasileiros

\begin{tabular}{|c|c|c|c|c|c|}
\hline Estado & $\begin{array}{l}2017 \\
\mathrm{n}(\%) \\
\end{array}$ & $\begin{array}{l}2019 \\
\mathrm{n}(\%) \\
\end{array}$ & Estado & $\begin{array}{l}2017 \\
\mathrm{n}(\%) \\
\end{array}$ & $\begin{array}{l}2019 \\
\mathrm{n}(\%) \\
\end{array}$ \\
\hline Região Sul & $19(10,2)$ & $24(13,4)$ & Paraíba & $3(1,61)$ & $3(1,6)$ \\
\hline Paraná & $10(5,37)$ & $11(6,1)$ & Pernambuco & $6(3,22)$ & $9(5,0)$ \\
\hline Rio Grande do Sul & $4(2,15)$ & $7(3,9)$ & Rio Grande do Norte & $2(1,07)$ & $3(1,6)$ \\
\hline Santa Catarina & $5(2,68)$ & $6(3,3)$ & Alagoas & $3(1,61)$ & $5(2,8)$ \\
\hline Região Sudeste & $72(38,7)$ & $67(37,6)$ & Sergipe & $5(2,68)$ & $4(2,2)$ \\
\hline São Paulo & $32(17,2)$ & $29(16,2)$ & Ceará & $7(3,76)$ & $8(4,4)$ \\
\hline Rio de Janeiro & $23(12,3)$ & $18(10,1)$ & Bahia & $15(8,06)$ & $14(7,8)$ \\
\hline Espírito Santo & $8(4,30)$ & $8(4,4)$ & Piauí & $2(1,07)$ & $1(0,5)$ \\
\hline Minas Gerais & $9(4,83)$ & $12(6,7)$ & Região Norte & $15(8,0)$ & $18(10,11)$ \\
\hline Região Centro-Oeste & $27(14,5)$ & $16(8,9)$ & Acre & $1(0,53)$ & -- \\
\hline Distrito Federal & $11(5,91)$ & $7(3,9)$ & Amazonas & $4(2,15)$ & $4(2,2)$ \\
\hline Goiás & $8(4,30)$ & $5(2,8)$ & Amapá & $1(0,53)$ & $1(0,5)$ \\
\hline Mato Grosso & $5(2,68)$ & $2(1,1)$ & Rondônia & $1(0,53)$ & -- \\
\hline Mato Grosso do Sul & $3(1,61)$ & $2(1,1)$ & Pará & $5(2,68)$ & $9(5,0)$ \\
\hline Região Nordeste & $48(25,8)$ & $53(29,7)$ & Tocantins & $3(1,61)$ & $3(1,6)$ \\
\hline Maranhão & $10(5,37)$ & $6(3,3)$ & Roraima & -- & $1(0,5)$ \\
\hline & & & Total & $186(100,0)$ & $178(100,0)$ \\
\hline
\end{tabular}

Fonte: Ministério da Educação [Internet]. e-MEC. 2017 [cited 2017 Mar 10]. Available from: http://portal.mec.gov.br/e-mec-sp-257584288.(8)

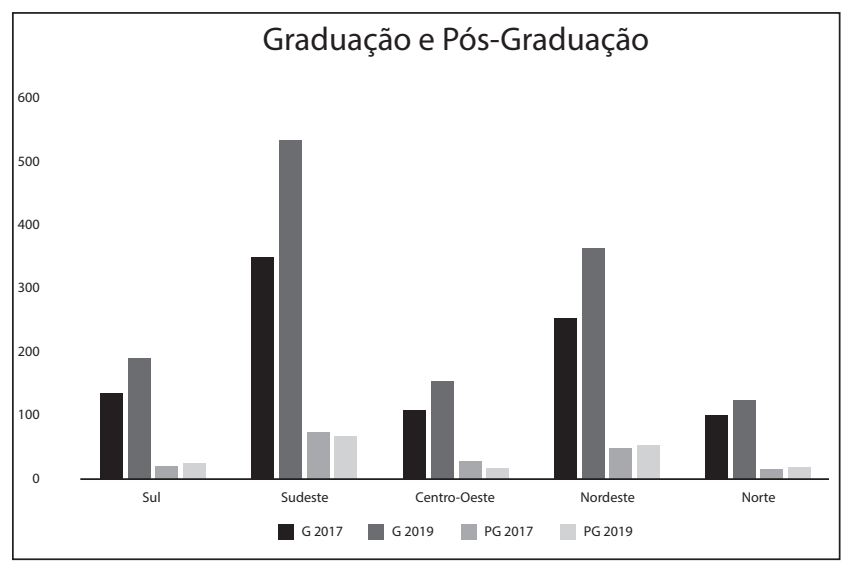

Fonte: Ministério da Educação [Internet]. e-MEC. 2017 [cited 2017 Mar 10]. Available from: http://portal.mec.gov.br/e-mec-sp-257584288. ${ }^{(8)}$

Figura 1. Distribuição dos cursos de pós-graduação em Enfermagem Pediátrica e/ou Neonatal em relação a existência de cursos de graduação em Enfermagem

fermagem Pediátrica e/ou Pediatria foram oito (4,3\%), com enfoque em Enfermagem Neonatal/Neonatologia e Pediátrica/Pediatria e vice-versa foram 52 (27,9\%) e Enfermagem Pediátrica e/ou Neonatal com outros enfoques associados foram cinco $(2,6 \%)$, em associação entre Enfermagem Obstétrica e Neonatal foram 10 $(5,3 \%)$ e Saúde da criança e do adolescente com quatro $(2,1 \%)$. Identificaram-se seis $(3,2 \%)$ ofertas na modalidade de cursos de residência com enfoque no neonato, criança e adolescente. Ainda, com enfoque em terapia intensiva, foram sete na área Neonatal (3,7\%), dois na Pediátrica $(1,0 \%), 20$ associados entre as áreas neona- tal e pediátrica e vice-versa $(10,7 \%)$ e três de terapia intensiva neonatal ou pediátrica associada a outras aéreas $(1,6 \%)$.

A modalidade presencial ( $\mathrm{n}=167 ; 90,8 \%$ ) predominou em relação ao ensino a distância-EAD, com 17 cursos (9,2\%). A carga horária mínima foi 360h/a, e a máxima, exceto as residências, 1224 h/a, com média de 469,1 h/a. O número de vagas variou de, no mínimo 20 a no máximo 5000, com média de 183,8. Seguindo o perfil da graduação, houve predomínio de oferta de vagas em instituições privadas, sendo quatro as instituições públicas. A modalidade EAD apresentou maior oferta de vagas, sendo mil por curso, embora um curso presencial tenha oferecido cinco mil vagas.

A análise do perfil, grade curricular, exigência de elaboração de monografia foi prejudicada, pois apesar da plataforma e-MEC disponibilizar espaço para consulta pública, contudo, não estavam acessíveis para todos os cursos, alguns constam apenas o parecer/ata de aprovação dos cursos pelas respectivas instituições. Desse modo, descrevem-se apenas aqueles que estavam disponíveis para consulta, em número de quatro $(2,23 \%) .{ }^{(8)}$

No perfil do curso predominou o curso de pós-graduação que qualifica enfermeiros para a sistematização do atendimento especializado de recém-nascidos, crianças e suas famílias, no âmbito ambulatorial e hospitalar, considerando o novo paradigma da promoção à saúde e da humanização da 
Quadro 1. Especificidades dos cursos de especialização em Enfermagem Neonatal $(n=8) /$ Neonatologia $(n=9)$, Enfermagem Pediátrica( $n=6) /$ Pediatria( $n=2)$, Enfermagem Neonatal e Pediátrica e vice-versa $(n=52)$ e Enfermagem Pediátrica e/ou Neonatal com outros enfoques associados $(n=5)$, Enfermagem Obstétrica e Neonatal $(n=10)$, Saúde da criança e do adolescente $(n=4)$ ativos no e-MEC $(n=96)$

\begin{tabular}{|c|c|c|c|c|c|c|}
\hline Instituição (IES) & Sigla & Denominação & Modalidade & $\begin{array}{l}\text { Carga } \\
\text { Horária }\end{array}$ & UF de Oferta & Vagas \\
\hline $\begin{array}{l}\text { Faculdade Israelita de Ciências da Saúde Albert } \\
\text { Einstein }\end{array}$ & FICSAE & Enfermagem Neonatal & Presencial & 420 & SP & 50 \\
\hline Centro Universitário de Volta Redonda & UNIFOA & Enfermagem Neonatal & Presencial & 360 & RJ & 30 \\
\hline $\begin{array}{l}\text { Faculdade de Enfermagem Nova Esperança de } \\
\text { Mossoró }\end{array}$ & FACENE/RN & Enfermagem Neonatal & Presencial & 360 & RN & 50 \\
\hline Faculdade Herrero & FATEC & Enfermagem Neonatal & Presencial & 380 & SC & 50 \\
\hline Universidade Castelo Branco & UCB & Enfermagem Neonatal & Presencial & 360 & RJ & 80 \\
\hline $\begin{array}{l}\text { Universidade do Grande Rio Professor José De } \\
\text { Souza Herdy }\end{array}$ & UNIGRANRIO & Enfermagem Neonatal & Presencial & 364 & RJ & 60 \\
\hline Universidade Estácio de Sá & UNESA & Enfermagem Neonatal & Presencial & 530 & $\begin{array}{l}\text { BA, CE, DF, PR, } \\
\text { RJ, SC, SP }\end{array}$ & 400 \\
\hline Instituto de Ensino Superior Múltiplo & IESM & Enfermagem Neonatal & Presencial & 400 & MA & 40 \\
\hline Centro Universitário São Camilo - Espírito Santo & SÃO CAMILO-ES & Enfermagem em Neonatologia & Presencial & 488 & ES & 35 \\
\hline Escola De Ensino Superior FABRA & FABRA & Enfermagem em Neonatologia & Presencial & 360 & ES & 5000 \\
\hline Faculdade São Camilo & FASC & Enfermagem em Neonatologia & Presencial & 560 & RJ & 30 \\
\hline Faculdade Conhecimento \& Ciência & FCC & Enfermagem em Neonatologia & Presencial & 420 & $\mathrm{PA}$ & 200 \\
\hline Faculdade Jardins & FAJAR & Enfermagem em Neonatologia & Presencial & 500 & BA, SE & 2000 \\
\hline Escola De Ensino Superior FABRA & FABRA & Enfermagem em Neonatologia & EAD & 360 & AM, ES & 1000 \\
\hline Centro Universitário São Camilo & SAO CAMILO & Enfermagem em neonatologia & Presencial & 444 & $\mathrm{SP}$ & 30 \\
\hline Faculdade Metropolitana de Ciencias e Tecnologia & FAMEC & Enfermagem em neonatologia & Presencial & 420 & PE, RN & 40 \\
\hline Faculdade de Santa Cruz da Bahia & FSC & Enfermagem em neonatologia & Presencial & 360 & $\mathrm{BA}$ & 50 \\
\hline Universidade Federal do Rio de Janeiro & UFRJ & Enfermagem Pediátrica & Presencial & 945 & RJ & 20 \\
\hline Faculdade EduCareMT & EDUCARE & Enfermagem Pediátrica & Presencial & 420 & MT & 80 \\
\hline Universidade FEEVALE & FEEVALE & Enfermagem Pediátrica & Presencial & 415 & RS & 30 \\
\hline Universidade Nilton Lins & UNINILTONLINS & Enfermagem Pediátrica & Presencial & 360 & AM & 35 \\
\hline Universidade Cidade de São Paulo & UNICID & Enfermagem Pediátrica & Presencial & 1224 & SP & 100 \\
\hline Faculdade Unyleya & - & Enfermagem Pediátrica & EAD & 360 & RJ & 200 \\
\hline Faculdade Conhecimento \& Ciência & FCC & Enfermagem em Pediatria & Presencial & 420 & $\mathrm{PA}$ & 200 \\
\hline Faculdade Metropolitana de Ciencias e Tecnologia & FAMEC & Enfermagem em Pediatria & Presencial & 420 & $\mathrm{PE}, \mathrm{RN}$ & 40 \\
\hline Centro Universitário Saúde ABC & CUSABC & Enfermagem Pediátrica e Neonatal & Presencial & 430 & SP & 40 \\
\hline $\begin{array}{l}\text { Faculdade Israelita de Ciências da Saúde Albert } \\
\text { Einstein }\end{array}$ & FICSAE & Enfermagem Pediátrica e Neonatal & Presencial & 420 & $\mathrm{SP}$ & 50 \\
\hline Centro Universitário do Sul de Minas & UNIS-MG & Enfermagem Pediátrica e Neonatal & Presencial & 420 & $M G$ & 40 \\
\hline Escola Superior da Amazônia & ESAMAZ & Enfermagem Pediátrica e Neonatal & Presencial & 380 & PA & 50 \\
\hline Centro Universitário Fametro & Unifametro & Enfermagem Pediátrica e Neonatal & Presencial & 480 & $\mathrm{CE}$ & 40 \\
\hline Faculdade de Medicina de São José do Rio Preto & FAMERP & Enfermagem Pediátrica e Neonatal & Presencial & 510 & $\mathrm{SP}$ & 60 \\
\hline CISNE - Faculdade De Quixadá & CFQ & Enfermagem Pediátrica e Neonatal & Presencial & 420 & $\mathrm{CE}$ & 30 \\
\hline Universidade Paranaense & UNIPAR & Enfermagem Pediátrica e Neonatal & Presencial & 360 & PR & 20 \\
\hline Centro Universitário UNIRB & UNIRB & Enfermagem Pediátrica e Neonatal & Presencial & 420 & $\mathrm{BA}$ & 100 \\
\hline Faculdades Integradas Ipitanga & FACIIP & Enfermagem Pediátrica e Neonatal & Presencial & 400 & $\mathrm{BA}$ & 200 \\
\hline Faculdade Einstein & - & Enfermagem Pediátrica e Neonatal & Presencial & 400 & $\mathrm{BA}$ & 200 \\
\hline Faculdade Cerrado & FACE & Enfermagem Pediátrica e Neonatal & Presencial & 420 & DF & 100 \\
\hline Centro Universitário Estácio do Recife & - & Enfermagem Neonatal e Pediátrica & Presencial & 409 & $\mathrm{PE}$ & 150 \\
\hline Universidade Salgado de Oliveira & UNIVERSO & Enfermagem Neonatal e Pediátrica & Presencial & 440 & $\mathrm{RJ}$ & 40 \\
\hline Faculdade Pernambucana de Saúde & FPS & Enfermagem Neonatal e Pediátrica & Presencial & 360 & $\mathrm{PE}$ & 30 \\
\hline Centro Universitário Celso Lisboa & UCL & Enfermagem Neonatal e Pediátrica & Presencial & 370 & RJ & 80 \\
\hline Centro Universitário de Barra Mansa & UBM & Enfermagem Neonatal e Pediátrica & Presencial & 420 & RJ & 30 \\
\hline Centro Universitário Augusto Motta & UNISUAM & Enfermagem Neonatal e Pediátrica & Presencial & 360 & RJ & 50 \\
\hline $\begin{array}{l}\text { Faculdade de Saúde d Desenvolvimento Humano } \\
\text { Santo Agostinho }\end{array}$ & FS & Enfermagem Neonatal e Pediátrica & Presencial & 360 & $M G$ & 35 \\
\hline Faculdade Telos & FATELOS & Enfermagem Neonatal e Pediátrica & Presencial & 480 & GO, MG, PR, SP & 100 \\
\hline
\end{tabular}


Continuação.

Centro Universitário Estácio da Amazônia

Universidade Castelo Branco

Centro Universitário Estácio de Sergipe

Universidade Estácio de Sá

Conservatório Brasileiro de Música - Centro

Universitário Brasileiro de Educação

Faculdade Alpha

Faculdade Estácio De Teresina

Centro Universitário Estácio do Ceará

Faculdade de Juazeiro do Norte

Universidade Cândido Mendes

Centro Universitário Cidade Verde

Faculdade Master de Parauapebas - FAMAP

Faculdade Dom Alberto

Faculdade Unyleya

Instituto de Ensino Superior Santa Cecília

Centro Universitário de Patos

Faculdade Venda Nova do Imigrante

FAVENI

Faculdade Apogeu

Faculdade do Bico do Papagaio

Faculdade Conhecimento \& Ciência

Centro Universitário Braz Cubas

Faculdade Futura

Faculdade de Ciências, Educação, Saúde,

Pesquisa e Gestão

Faculdade da Região Serrana

Escola Bahiana de Medicina e Saúde Pública

Faculdade de Ciências Humanas e Exatas do

Sertão do São Francisco

Centro Universitário São Camilo

Faculdade Metropolitana do Vale do Aço

Faculdade Batista de Minas Gerais

Faculdade José Lacerda Filho de Ciências

Aplicadas

Pontifícia Universidade Católica de Goiás

Faculdade Integrada da Amazônia

Faculdade Telos

Centro Universitário Cidade Verde

\begin{tabular}{|c|c|c}
\hline ESTÁCIO AMAZÔNIA & Enfermagem Neonatal e Pediátrica \\
UCB & Enfermagem Neonatal e Pediátrica \\
- & Enfermagem Neonatal e Pediátrica \\
UNESA & Enfermagem Neonatal e Pediátrica \\
\hline CBM-UniCBE & Enfermagem Neonatal e Pediátrica \\
& \\
\hline Alpha & Enfermagem Neonatal e Pediátrica \\
ESTÁCIO TERESINA & Enfermagem Neonatal e Pediátrica \\
\hline Estácio FIC & Enfermagem Neonatal e Pediátrica \\
\hline FJN & Enfermagem Neonatal e Pediátrica \\
\hline UCAM & Enfermagem Pediátrica e Neonatal \\
UNIFCV & Enfermagem Neonatal e Pediátrica \\
FAMAP & Enfermagem em Pediatria e Neonatal \\
\hline FDA & Enfermagem em pediatria e
\end{tabular}

Presencial

Presencial

Presencial

Presencial

Presencial neonatologia

Enfermagem em Pediatria e Neonatologia

Enfermagem em Pediatria e Neonatologia

Enfermagem em Pediatria e Neonatologia

Enfermagem em Pediatria e Neonatologia

Presencia

Presencial

Presencial

Presencial

EAD

EAD

\begin{tabular}{|c|c|c|}
\hline 409 & RR & 60 \\
\hline 360 & RJ & 120 \\
\hline 390 & SE & 400 \\
\hline 391 & RJ & 400 \\
\hline
\end{tabular}

Presenc
EAD

360

EAD

EAD

510
390

RJ

391

460

360
480

480

PE

E

\begin{tabular}{|l}
50 \\
60
\end{tabular} 


\begin{tabular}{|c|c|c|c|c|c|c|}
\hline Faculdade Futura & - & $\begin{array}{l}\text { Enfermagem em Pediatria e Saúde } \\
\text { Mental }\end{array}$ & EAD & 720 & $\mathrm{SP}$ & 300 \\
\hline Faculdade da Região Serrana & FARESE & $\begin{array}{l}\text { Enfermagem em Pediatria e Saúde } \\
\text { Mental }\end{array}$ & EAD & 720 & ES & 300 \\
\hline Universidade do Extremo Sul Catarinense & UNESC & Enfermagem Obstétrica e Neonatal & Presencial & 485 & SC & 30 \\
\hline Instituto Florence de Ensino Superior & IFES & Enfermagem Obstétrica e Neonatal & Presencial & 470 & MA & 120 \\
\hline Faculdade Pitágoras de Londrina & - & Enfermagem Obstétrica e Neonatal & Presencial & 600 & PR & 25 \\
\hline Faculdade São Sebastião & - & Enfermagem Obstétrica e Neonatal & Presencial & 460 & $\mathrm{SP}$ & 50 \\
\hline Universidade do Ceuma - Uniceuma & UNICEUMA & Enfermagem Obstétrica e Neonatal & Presencial & 400 & $\mathrm{MA}$ & 25 \\
\hline $\begin{array}{l}\text { Faculdade de Ciências Médicas de Campina } \\
\text { Grande }\end{array}$ & FCM & Enfermagem Obstétrica e Neonatal & Presencial & 600 & PB & 40 \\
\hline Faculdade Pitágoras de Feira de Santana & - & Enfermagem Obstétrica e Neonatal & Presencial & 400 & $\mathrm{BA}$ & 100 \\
\hline Faculdade Pitágoras de Linhares & - & Enfermagem Obstétrica e Neonatal & Presencial & 608 & ES & 100 \\
\hline Faculdade Pitágoras de Belo Horizonte & FPAS & Enfermagem Obstétrica e Neonatal & Presencial & 400 & MG & 26 \\
\hline Centro Universitário FG & UNIFG & $\begin{array}{l}\text { Enfermagem em Neonatologia e } \\
\text { Obstetrícia }\end{array}$ & Presencial & 404 & SE & 60 \\
\hline Faculdade de Ampére & FAMPER & $\begin{array}{l}\text { Enfermagem em pediatria e saúde da } \\
\text { criança }\end{array}$ & Presencial & 420 & PR & 20 \\
\hline Universidade de Araraquara & UNIARA & Enfermagem em saúde da criança & EAD & 360 & $\mathrm{SP}$ & 450 \\
\hline Universidade Cidade de São Paulo & UNICID & $\begin{array}{l}\text { Enfermagem em saúde da criança e } \\
\text { do adolescente }\end{array}$ & Presencial & 1224 & $\mathrm{SP}$ & 100 \\
\hline Faculdade Inspirar & Inspirar & $\begin{array}{c}\text { Enfermagem em saúde da criança e } \\
\text { neonatal }\end{array}$ & Presencial & 360 & PR & 60 \\
\hline
\end{tabular}

Fonte: Ministério da Educação [Internet]. e-MEC. 2017 [cited 2017 Mar 10]. Available from: http://portal.mec.gov.br/e-mec-sp-257584288.(8)

Quadro 2. Especificidades dos cursos de residência com enfoque no neonato, criança e adolescente ativos no e-MEC ( $n=6$ )

\begin{tabular}{|c|c|c|c|c|c|c|}
\hline Instituição(IES) & Sigla & Denominação & Modalidade & $\begin{array}{c}\text { Carga } \\
\text { Horária }\end{array}$ & UF de Oferta & Vagas \\
\hline Universidade Salvador & UNIFACS & $\begin{array}{c}\text { Residência multiprofissional em saúde } \\
\text { da criança e do adolescente }\end{array}$ & Presencial & 5760 & $\mathrm{BA}$ & 50 \\
\hline Universidade do Estado do Amazonas & UEA & $\begin{array}{l}\text { Programa de Residência em } \\
\text { Enfermagem Neonatal }\end{array}$ & Presencial & 5760 & AM & 2 \\
\hline Pontifícia Universidade Católica de Campinas & PUC-CAMPINAS & $\begin{array}{l}\text { Multiprofissional em Saúde - Saúde } \\
\text { da Criança }\end{array}$ & Presencial & 5768 & SP & 14 \\
\hline $\begin{array}{l}\text { Pontifícia Universidade Católica do Rio Grande } \\
\text { do Sul }\end{array}$ & PUCRS & $\begin{array}{l}\text { PREMUS - Saúde da Criança e do } \\
\text { Adolescente }\end{array}$ & Presencial & 5775 & RS & 6 \\
\hline Universidade Federal do Rio Grande Do Sul & UFRGS & $\begin{array}{l}\text { Residência integrada em saúde da } \\
\text { criança: violências e vulnerabilidades }\end{array}$ & Presencial & 5760 & RS & 24 \\
\hline Universidade Federal do Rio de Janeiro & UFRJ & $\begin{array}{l}\text { Residência Multiprofissional } \\
\text { Integrada em Saúde da Criança e do } \\
\text { Adolescente }\end{array}$ & Presencial & 5760 & RJ & 12 \\
\hline
\end{tabular}

Fonte: Ministério da Educação [Internet]. e-MEC. 2017 [cited 2017 Mar 10]. Available from: http://portal.mec.gov.br/e-mec-sp-257584288. ${ }^{(8)}$

Quadro 3. Especificidades dos cursos de especialização em Terapia Intensiva Neonatal $(n=7)$, Terapia Intensiva Pediátrica $(n=2)$, Terapia intensiva neonatal e pediátrica e vice-versa $(n=20)$, terapia intensiva neonatal ou pediátrica associada a outras aéreas $(n=3)$, ativos no e-MEC ( $n=32)$

\begin{tabular}{|c|c|c|c|c|c|c|}
\hline Instituição(IES) & Sigla & Denominação & Modalidade & $\begin{array}{c}\text { Carga } \\
\text { Horária }\end{array}$ & UF de Oferta & Vagas \\
\hline Centro Universitário da Fundação Herminio Ometto & FHO & $\begin{array}{c}\text { Enfermagem em Terapia Intensiva } \\
\text { Neonatal } \\
\end{array}$ & Presencial & 515 & $\mathrm{SP}$ & 30 \\
\hline Universidade Feevale & FEEVALE & $\begin{array}{l}\text { Enfermagem em Terapia Intensiva } \\
\text { Neonatal } \\
\end{array}$ & Presencial & 364 & RS & 35 \\
\hline Faculdade Inspirar & Inspirar & $\begin{array}{l}\text { Enfermagem em terapia intensiva } \\
\text { neonatal }\end{array}$ & Presencial & 360 & MA & 60 \\
\hline $\begin{array}{l}\text { Faculdade de Ciências Médicas da Santa Casa } \\
\text { São Paulo }\end{array}$ & FCMSCSP & $\begin{array}{c}\text { Enfermagem em Neonatologia e UTI } \\
\text { Neonatal }\end{array}$ & Presencial & 500 & $\mathrm{SP}$ & 30 \\
\hline $\begin{array}{l}\text { Centro Universitário das Faculdades Metropolitanas } \\
\text { Unidas }\end{array}$ & FMU & $\begin{array}{l}\text { Enfermagem em Neonatologia } \\
\text { Intensiva }\end{array}$ & Presencial & 400 & SP & 60 \\
\hline
\end{tabular}


Continuação.

\begin{tabular}{|c|c|c|c|c|c|c|}
\hline Faculdade Conhecimento \& Ciência & FCC & $\begin{array}{l}\text { Enfermagem em Unidade de Terapia } \\
\text { Intensiva Neonatal }\end{array}$ & Presencial & 360 & PA & 200 \\
\hline Universidade Salvador & UNIFACS & $\begin{array}{c}\text { Especialização em Cuidados Críticos: } \\
\text { Enfermagem na Terapia Intensiva } \\
\text { Neonatal }\end{array}$ & Presencial & 450 & $\mathrm{BA}$ & 50 \\
\hline Faculdade Sequencial & - & $\begin{array}{l}\text { Enfermagem em unidade de terapia } \\
\text { intensiva pediátrica }\end{array}$ & Presencial & 400 & SP & 1000 \\
\hline $\begin{array}{l}\text { Faculdade de Ciências Médicas da Santa Casa } \\
\text { São Paulo }\end{array}$ & FCMSCSP & $\begin{array}{l}\text { Enfermagem Pediátrica e UTI } \\
\text { Pediátrica }\end{array}$ & Presencial & 500 & SP & 30 \\
\hline Pontifícia Universidade Católica de Minas Gerais & PUC MINAS & $\begin{array}{l}\text { Enfermagem em unidade de terapia } \\
\text { intensiva neonatal e pediátrica }\end{array}$ & Presencial & 360 & MG & 30 \\
\hline Faculdade CGESP & - & $\begin{array}{c}\text { Enfermagem em terapia intensiva } \\
\text { neonatal e pediátrica }\end{array}$ & EAD & 420 & G0 & 1000 \\
\hline Faculdade Inspirar & Inspirar & $\begin{array}{c}\text { Enfermagem em terapia intensiva } \\
\text { neonatal e pediátrica }\end{array}$ & Presencial & 360 & ES & 60 \\
\hline Faculdade Santa Casa de Belo Horizonte & FSCBH & $\begin{array}{c}\text { Enfermagem em terapia intensiva } \\
\text { neonatal e pediátrica }\end{array}$ & Presencial & 440 & MG & 30 \\
\hline $\begin{array}{l}\text { Faculdade José Lacerda Filho de Ciências } \\
\text { Aplicadas }\end{array}$ & FAJOLCA & $\begin{array}{l}\text { Enfermagem em terapia intensiva } \\
\text { neonatal e pediátrica - Recife/PE }\end{array}$ & Presencial & 504 & PE & 40 \\
\hline FI - Faculdade Iguaçu & $\mathrm{FI}$ & $\begin{array}{l}\text { Enfermagem em Unidade de Terapia } \\
\text { Intensiva Neonatal e Pediátrica }\end{array}$ & Presencial & 360 & MS & 30 \\
\hline Faculdade de Ciências Humanas & IMENSU & $\begin{array}{c}\text { Enfermagem em Terapia Intensiva } \\
\text { Pediátrica e Neonatal }\end{array}$ & Presencial & 420 & SP & 60 \\
\hline Faculdade Associada Brasil & FAB & $\begin{array}{l}\text { Enfermagem em Terapia Intensiva } \\
\text { Pediátrica e Neonatal }\end{array}$ & Presencial & 480 & SP & 60 \\
\hline Faculdade XV de Agosto & FAQ & $\begin{array}{l}\text { Enfermagem em terapia intensiva } \\
\text { pediátrica e neonatal }\end{array}$ & Presencial & 420 & $\begin{array}{l}\text { AL, BA, RS, } \\
\text { SC, SP }\end{array}$ & 50 \\
\hline Faculdade Interativa de São Paulo & FAISP & $\begin{array}{l}\text { Enfermagem em terapia intensiva } \\
\text { pediátrica e neonatal }\end{array}$ & Presencial & 450 & BA, MG, SP & 50 \\
\hline Faculdade Gennari e Peartree & FGP & $\begin{array}{l}\text { Enfermagem em terapia intensiva } \\
\text { pediátrica e neonatal }\end{array}$ & Presencial & 450 & $\mathrm{AL}, \mathrm{SP}$ & 50 \\
\hline Escola Superior da Amazônia & ESAMAZ & $\begin{array}{c}\text { Enfermagem em terapia intensiva } \\
\text { pediátrica e neonatal }\end{array}$ & Presencial & 360 & PA & 50 \\
\hline Faculdade Master de Parauapebas & FAMAP & $\begin{array}{l}\text { enfermagem em unidade terapia } \\
\text { intensiva pediátrica e neonatal }\end{array}$ & EAD & 540 & PA & 300 \\
\hline Centro Universitário Redentor & FACREDENTOR & $\begin{array}{l}\text { Enfermagem em Neonatologia e } \\
\text { Pediatria Intensiva }\end{array}$ & Presencial & 360 & $\mathrm{PE}$ & 100 \\
\hline Instituto de Desenvolvimento Educacional & IDE & $\begin{array}{l}\text { Enfermagem em neonatologia e } \\
\text { pediatria intensiva }\end{array}$ & Presencial & 360 & PE & 50 \\
\hline Instituto Superior de Educação do CECAP & ISCECAP & $\begin{array}{c}\text { Assistência e UTI em Enfermagem } \\
\text { Neonatal e Pediátrica }\end{array}$ & Presencial & 380 & DF & 200 \\
\hline Faculdade Laboro & Laboro & $\begin{array}{c}\text { Assistência e UTI em Enfermagem } \\
\text { Neonatal e Pediátrica }\end{array}$ & Presencial & 380 & DF, MA, TO & 100 \\
\hline Centro Universitário Amparense & UNIFIA & $\begin{array}{c}\text { Enfermagem Neonatal e Pediátrica } \\
\text { com Ênfase em UTI }\end{array}$ & Presencial & 371 & SP & 50 \\
\hline $\begin{array}{l}\text { Instituto Superior da Convenção Nac. das } \\
\text { Assembleias de Deus }\end{array}$ & ISCON & $\begin{array}{l}\text { Especialização Lato Sensu em } \\
\text { Assistência e UTI e Enfermagem } \\
\text { Neonatal e Pediátrica }\end{array}$ & Presencial & 700 & DF & 100 \\
\hline Faculdades Pequeno Príncipe & FPP & $\begin{array}{c}\text { Enfermagem em Pediatria e Cuidados } \\
\text { Intensivo Neonatais }\end{array}$ & Presencial & 360 & PR & 50 \\
\hline Centro Universitário Ateneu & - & $\begin{array}{c}\text { Enfermagem em Obstetrícia, Saúde da } \\
\text { Criança e UTI Neonatal }\end{array}$ & Presencial & 384 & CE & 30 \\
\hline $\begin{array}{l}\text { Faculdade de Ciências Médicas e da Saúde de } \\
\text { Juiz de Fora }\end{array}$ & FCMS/JF & $\begin{array}{l}\text { Enfermagem em Terapia Intensiva } \\
\text { Neonatal e Adulto }\end{array}$ & Presencial & 450 & $M G$ & 40 \\
\hline Centro Universitário São Camilo & SAO CAMILO & $\begin{array}{l}\text { Enfermagem Pediátrica em UTI e } \\
\text { Centro Cirúrgico }\end{array}$ & Presencial & 472 & SP & 30 \\
\hline
\end{tabular}

Fonte: Ministério da Educação [Internet]. e-MEC. 2017 [cited 2017 Mar 10]. Available from: http://portal.mec.gov.br/e-mec-sp-257584288. ${ }^{(8)}$

assistência, aliado a inovação tecnológica, sendo o especialista em Enfermagem Neonatal e Pediátrica, capaz de prestar assistência ao neonato, à criança e suas famílias, em todos os níveis de atenção, entendendo o processo saúde-doença desses pacientes no contexto sócio familiar. 
As disciplinas mencionadas foram: Assistência à Saúde da Criança e a Enfermagem; Assistência à Saúde do Neonato e a Enfermagem; Assistência de Enfermagem Neonatal ao RN de Alto Risco; Assistência de Enfermagem Neonatal ao RN de Baixo e Médio Risco; Didática do Ensino Superior (disciplina adicional); Enfermagem Pediátrica à Criança de Alto Risco, Baixo e Médio Risco; Visitas Técnicas no Cenário Neonatal e Pediátrico; Metodologia da Pesquisa; Legislação e Histórico das Políticas de Saúde (disciplina adicional); Regulamentação e Organização do Sistema Único de Saúde (disciplina adicional); Tecnologias para o Cuidado ao RN e à Criança; Assistência ao Neonato e Família; Administração do Serviço de Enfermagem em Pediatria; Aspectos Epidemiológicos e Sociais em Neonatologia e Pediatria; Controle de Infecção e Gerenciamento de Resíduos; Assistência na Ventilação Mecânica e nas Intercorrências Cardíacas no Neonato e na Criança; Ética e Bioética; Aleitamento materno, Iniciativa do Hospital Amigo da Criança e Projeto Mãe-Canguru: atuação da enfermagem; Alojamento conjunto: comunicação com a família e orientações sobre cuidados gerais do RN; Vacinação e os testes de triagem no período neonatal; Principais problemas no neonato: condutas de enfermagem; AIDPI neonatal; A avaliação da dor no neonato e Coleta de exames no neonato; Transporte/transferência do neonato/Morte neonatal. A maioria dos cursos exige a realização de monografia para a conclusão do curso.

Em síntese, o perfil encontrado da pós-graduação lato-sensu em enfermagem pediátrica e neonatológica no país evidencia que a maioria dos cursos ofertados é na modalidade especialização $(96,7 \%)$, concentrados no sudeste $(37,6 \%)$, ofertados por instituições privadas $(97,8 \%)$, com predomínio de cursos de especialização em enfermagem pediátrica e neonatal associados $(27,9 \%)$, na modalidade presencial $(90,8 \%)$, com carga horária média de 469,1 h/a, com oferta média de vagas de 183,8 e poucos cursos disponibilizam o projeto pedagógico online no site do ministério da educação $(2,1 \%)$.

\section{Discussão}

Reconhece-se o desafio de formar e capacitar trabalhadores para o SUS de modo a atender às necessidades de saúde da população. Isso implica envidar esforços para conhecer os processos educativos no campo da formação na saúde e especificamente na Enfermagem, pois ao conhecê-los tem-se subsídios para promover e fortalecer essa formação.

No setor saúde, cuja intensa e acelerada incorporação tecnológica não agrega a capacidade de substituir o trabalhador pela tecnologia, há cada vez mais necessidade de profissionais capacitados a atuar. Desse modo, os cursos da área da saúde têm sido ampliados nas últimas décadas, com aumento de $218 \%$ de 2000 até 2012. A enfermagem é exemplo dessa realidade, com a criação, entre 2000 e 2012, de 684 novos cursos. $^{(10)}$

Ademais, a análise proposta nesse estudo está em consonância com o compromisso assumido pela Organização Pan-Americana da Saúde (Opas), em 2017, a qual aprovou estratégia para estabelecer mecanismos formais para superar os problemas de recursos humanos em saúde (RHS) elencando como prioridades, dentre outras: “a transformação da educação das profissões da saúde; o desenvolvimento de equipes interprofissionais nas redes de serviços mediante a formação interprofissional e a diversificação dos contextos de aprendizagem; e a promoção da integração dos setores da educação e da saúde visando alinhar a formação de RHS às necessidades dos sistemas de saúde".(11)

Ao longo da história da enfermagem no país, observou-se que contradições sociais permearam a realidade da formação desse profissional e a relevância econômica foi determinante nas políticas adotadas em cada período histórico, levando a fragmentação da profissão(12) e ao dissenso que compõe os currículos atualmente e induziram a oferta de cursos pela iniciativa privada e na modalidade à distância. Assim, prevaleceu a lógica de mercado, tornando o setor educacional rentável para as instituições de ensino privadas, espelhando a desconexão dos setores educação e saúde e com as necessidades sanitárias das populações das regiões menos desenvolvidas e socialmente mais

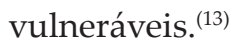

Desse modo, embora tenha havido crescimento expressivo da graduação em Enfermagem no país, esse ficou concentrado na região sudeste e em instituições privadas. Em estudo(14) para analisar a produção científica sobre docência em saúde no Brasil, visando identificar os principais temas de investiga- 
ção, abordagens e as possíveis lacunas do conhecimento, encontrou-se maior concentração de cursos na região Sudeste $(55,55 \%)$, seguida da região Sul $(18,18 \%)$ e Nordeste $(17,17 \%)$, a exemplo de nossos resultados.

Em estudo ${ }^{(13)}$ para analisar a trajetória dos catorze cursos de graduação em saúde, apontar a ociosidade de vagas e identificar a presença e a dimensão da educação a distância, encontrou-se como resultados que houve expressivo aumento da oferta de cursos e, especificamente na Enfermagem, de 108 para 887 (721,3\%). Essa expansão foi comandada primordialmente pelas instituições privadas de ensino, conforme evidenciado em nosso estudo. Em 2015, apresentavam uma oferta de 4.105 cursos $(79,0 \%)$ do total de 5.222 cursos das graduações em saúde no País, representando $82 \%$ na Enfermagem.

Outra característica evidenciada pelo estudo foi a iniquidade geográfica na oferta dos cursos de graduação na área de saúde no Brasil. Em 1995, do total dos cursos, 51,9\% estavam concentrados na região Sudeste; $20,9 \%$ no Sul; $15,6 \%$ no Nordeste; e apenas $7,0 \%$ no Centro-Oeste e $4,6 \%$ na região Norte. Em 2015, o Sudeste concentrava $45,4 \%$ do total dos cursos (São Paulo, com 23,8\%, e Minas Gerais com $12,3 \%$ do total dos cursos no País), e mais da metade do total dos cursos (54,6\%) estava distribuída em: $20,3 \%$ no Nordeste; $18,2 \%$ no Sul; $8,8 \%$ no Centro Oeste; e 7,3\% no Norte. ${ }^{(13)}$ Daí em diante, os dados permanecem inalterados, conforme observamos em nosso estudo.

Em convergência com os dados de nosso estudo, em que se evidenciou a presença da modalidade educação a distância, autores ${ }^{(13)}$ apontam também a realidade da formação a distância, em que, apesar da expressiva oferta de vagas nessa modalidade, a partir de 2010, a Enfermagem teve 475 concluintes. Essa tem sido uma preocupação da profissão, pois independentemente do quantitativo, essa formação exige uma base teórica sólida e o desenvolvimento de habilidades adquiridas com a prática das técnicas, pontos altamente vulneráveis na formação a distância, tendo em vista a precariedade dos polos, os quais são insuficientes em termos de qualidade para aulas presenciais e práticas dos alunos, sem convênios com instituições de saúde para estágios, sem bibliotecas e com larga utilização de professores recém-formados, com pouca ou nenhuma experiência no ensino e nem formação didática.

Em estudo que analisou os aspectos gerais da formação profissional dos trabalhadores de enfermagem, os autores encontraram resultados semelhantes aos que evidenciamos neste estudo. A formação é realizada principalmente no setor privado e na região Sudeste. Os autores alertam que as políticas públicas existentes não têm sido efetivas no sentido de desconcentrar o aparelho formador e o financiamento, bem como reverter o quadro de desequilíbrio entre oferta e demanda de profissionais..$^{(10)}$

Além disso, a pesquisa ${ }^{(10)}$ chamou a atenção dos pesquisadores em relação a concentração dos cursos em três dos 27 estados da federação, que são responsáveis pela formação de quase metade $(46,1 \%)$ dos enfermeiros do país, sendo eles São Paulo $(24,6 \%)$, Rio de Janeiro (11,1\%) e Minas Gerais (10,4\%). Seguiram-se Rio Grande do Sul (5,3\%), Paraná (5,0\%) e Bahia $(6,3 \%)$. Ou seja, concentração do aparato formador na região Sudeste representada por quase a metade do contingente de cursos (48,2\%). A região Nordeste foi a segunda que mais formou no país, responsável pela graduação de $23,5 \%$; seguida pela região Sul, com $12,8 \%$. Já as regiões Centro-Oeste e Norte são as que menos contribuem para a formação destes profissionais, somando $12,4 \%$.

Em relação a formação especializada, no país, historicamente, a formação acadêmica na pós-graduação não se tornou relevante no cenário de trabalho, em consonância as necessidades dos órgãos públicos e particulares. Autores ${ }^{(12)}$ afirmam que, apesar do modelo de assistência adotado pela previdência no Brasil, que determinou a ampliação do campo prático de enfermagem, foram os órgãos públicos que absorveram mais profissionais de nível superior, enquanto o setor privado absorveu as categorias de auxiliares e técnicos de enfermagem, em razão da política de redução de custos, o que se perpetua até hoje.

Isso influenciou e segue influenciando a formação, em função da redução de despesas, observada na educação em Enfermagem no passado, quando os currículos passaram a privilegiar o ensino especializado e a assistência curativa, havendo proliferação de cursos de menor custo, como os que foram organizados para auxiliares e técnicos de Enfermagem e que hoje se refletem na oferta ampliada de vagas em instituições 
privadas, em período noturno, com carga horária mínima preconizada nas diretrizes curriculares. ${ }^{(12)}$

O mesmo ocorre com a oferta de cursos de especialização. Em comparação com estudos ${ }^{(13-15)}$ na região metropolitana de Salvador, Bahia resultado similares a esses foram encontrados, com predomínio de especializações em instituições de ensino privadas $(90 \%)$, similar ao nosso estudo, com $97,8 \%$, bem como predomínio de especializações na modalidade presencial (70\%), e 90,8\% em nossa pesquisa. Com relação a carga horária predominante no presente estudo, também foi similar ao estudo mencionado, pois $68 \%$ das especializações tinha carga horária maior que 360 horas.

Semelhante aos dados de nossa pesquisa, sobre a formação na pós-graduação lato sensu, nas diversas áreas de conhecimento, estudo ${ }^{(10)}$ encontrou que $7,5 \%$ dos enfermeiros cursou residência e 72,8\% especialização. Mesmo apresentando baixa oferta de vagas/alunos, o Programa de Residência é, hegemonicamente, oferecido pelas instituições públicas (76,1\%), contra $18,4 \%$ nas privadas. Dentre aqueles que fizeram especialização, 66,8\% realizaram em instituições privadas; $30,7 \%$ nas públicas e pouco mais de $1 \%$ nas filantrópicas. Os autores registram que, sendo a Especialização a forma que mais de $70 \%$ utilizaram para se qualificar, ela se deu, hegemonicamente, em instituições de iniciativa privada, mediante pagamento, recaindo, quase sempre, para o próprio profissional a responsabilidade e o ônus da formação. Ou seja, o poder público ficou à margem do processo, não se responsabilizando de fato pela formação especializada desses profissionais, fundamentais ao Sistema Único de Saúde, embora haja uma política nacional de educação permanente, instituída desde 2004. ${ }^{(16)}$

Evidenciou-se nos dados desse estudo a oferta de especialização com enfoque em terapia intensiva na área de enfermagem pediátrica e neonatal, convergente com o estudo ${ }^{(17)}$ para identificar as principais necessidades de qualificação da equipe de enfermagem quanto ao seu processo de trabalho na Unidade de Terapia Intensiva Pediátrica, que encontrou como necessidades de qualificação as assistenciais, destacando-se a administração de medicamentos e suas interações, a assistência ao paciente na Parada Cardiorrespiratória (RCP) e na Ventilação Mecânica (VM); as gerenciais, com temas como a Sistematização da Assistência de Enfermagem (SAE), implementação dos protocolos de procedimentos e da rotina admissional na UTI; e, as ações ético-sociais, com abordagem sobre humanização e cuidados paliativos. Os autores reforçam a importância do processo de qualificação da equipe de enfermagem para atuar nas unidades de terapia intensiva.

Situação similar foi encontrada nos dados de estudo $^{(18)}$ para identificar o perfil do profissional enfermeiro que atua em UTI. As autoras elencaram a necessidade do desenvolvimento profissional com atualização técnico-científica por meio de treinamentos, especializações e pós-graduação, indicando que deve haver reflexão dos enfermeiros e gestores dos serviços de saúde quanto ao perfil adequado ao desenvolvimento de atividades em unidades de alta complexidade.

Corroborando essa percepção da necessidade de atualização para o enfermeiro que trabalha com neonatos e crianças, autores defendem que esses profissionais prescindem de habilidades especificas e sustentam a importância das competências específicas avançadas do enfermeiro neonatal e pediátrico, embora essas habilidades não estejam claramente definidas na literatura. ${ }^{(19)}$

Ainda, a oferta dos cursos de residência, que poderia oferecer a formação de prática avançada mencionada, ocorre em pequeno número no país, conforme percebe-se nos achados desse estudo, artigo sobre a residência em gerência de serviços de Enfermagem identificou o quanto a prática em serviço aliada a competências propostas e desenvolvidas durante o curso ampliaram a visão dos enfermeiros no gerenciamento das unidades onde atuam. As autoras afirmam que os participantes escolheram a residência devido à necessidade de fazerem um curso de especialização e indicam que a residência proporcionou segurança e experiência profissional embasando o enfermeiro no desenvolvimento de atividades científicas, estimulando o aprimoramento profissional. ${ }^{(20)}$

Ainda sobre as residências, em estudo ${ }^{(21)}$ para analisar as produções científicas dos anos de 2012 a 2016, referentes à importância dos programas de residência para o processo ensino-aprendizagem em enfermagem, os autores concluem que a residência é capaz de propiciar maior segurança ao enfermei- 
ro, suprindo lacunas da graduação e proporcionar melhorias no atendimento ao paciente, no entanto, o processo ensino-aprendizagem requer aperfeiçoamento e investimentos nos enfermeiros preceptores. Ao que acrescentamos a necessária ampliação no número de vagas, pois a quantidade de cursos é irrisória no país.

Percebe-se nesse estudo que a oferta de pós-graduação lato-sensu nas áreas de Enfermagem Pediátrica e Neonatal, em comparação com a oferta de cursos de graduação é pequena. Um fator de influência, apontado em estudo ${ }^{(22)}$ realizado em Portugal, que analisou as expectativas profissionais de enfermeiros que frequentaram cursos de especialização, é que poucas mudanças ocorreram na vida profissional destes após a conclusão da formação especializada. Isso poderia influenciar tanto na oferta de vagas quanto na procura por essa modalidade de capacitação profissional. Os autores encontraram que não houve mudança na carreira profissional após a conclusão do curso de especialização, embora tenha havido contribuição do curso para o desenvolvimento do conhecimento, da prestação de cuidados aos pacientes e, consequentemente, maior competência profissional. Ao que acrescentamos como motivo para ampliação na oferta de especialização para uma atuação mais segura e eficaz.

\section{Conclusão}

Houve predomínio de oferta de cursos de pós-graduação lato sensu, na modalidade especialização, com concentração na Região Sudeste, ofertados por instituições privadas, na área de enfermagem pediátrica e neonatal, do tipo presencial, com carga horária entre 400 a 499 horas, com oferta de 81 a 100 vagas e não disponibilização do projeto pedagógico dos cursos no portal do E-mec para consulta pública. Nesse sentido, torna-se necessário ampliar o debate sobre a qualidade da formação do especialista em enfermagem pediátrica e neonatal, incluindo o enfoque da abordagem de prática profissional desejado, o status social do profissional especialista, seus rendimentos e expertise adquirida após a qualificação, não somente em função das demandas do mercado de trabalho, mas em convergência para a formação de recursos humanos para o Sistema Único de Saúde. A preocupação com o preparo científico e intelectual do profissional em enfermagem pediátrica e neonatal deve enfocar as competências requeridas desse profissional, com discussões a respeito da postura crítica e reflexiva condicionada à realidade social. Aponta-se como limitação do estudo a ausência dos projetos pedagógicos online para que pudesse ser realizada uma avaliação dos conteúdos oferecidos. Recomenda-se à SOBEP liderar a discussão acerca da formação do especialista, apontando as competências desse profissional, a fim de direcionar a proposição do currículo mínimo com atenção especial aos conteúdos oferecidos, a carga horária, as atividades teóricas e as teórico-práticas mínimas que garantam uma formação de qualidade. Ademais, recomenda-se que haja melhor distribuição na oferta desses cursos em todo o território nacional assim como o incremento na oferta de cursos de residência em enfermagem nessas áreas do conhecimento.

\section{Contribuições}

Conterno JR, Toso BRGO, Rodrigues EC, Mandetta MY contribuíram com a concepção do estudo, análise e interpretação dos dados, redação do artigo, revisão crítica relevante do conteúdo intelectual e aprovação final da versão a ser publicada.

\section{Referências}

1. Brasil. Ministério da Saúde. Portaria 1130/2015. Institui a Política Nacional de Atenção Integral à Saúde da Criança (PNAISC) no âmbito do Sistema Único de Saúde. Brasília (DF): Ministério da Saúde; 2015.

2. Vieira DS, Santos NC, Nascimento JA, Collet N, Toso BR, Reichert AP. A prática do enfermeiro na consulta de puericultura na estratégia saúde da família. Texto Contexto Enferm. 2018; 27(4):e4890017.

3. Fernandes JD. Diretrizes curriculares e projetos pedagógicos de cursos de graduação em enfermagem. In: Teixeira E, Vale EG, Fernandes JD, Sordi MRL (orgs). 0 ensino de graduação em enfermagem no Brasil: 0 ontem, 0 hoje e 0 amanhã. Brasília: Instituto Nacional de Estudos e Pesquisas Educacionais Anísio Teixeira; 2006. 244p.

4. Brasil. Ministério da Educação. Resolução CNE/CES 3/2001. Institui as diretrizes curriculares nacionais do curso de graduação em enfermagem [Internet]. Brasília (DF): Ministério da Saúde; 2001.

5. Cabral IE, Teixeira E, Fernandes JD, Andrade AC, Silva, KL, Rocha ME, et al. Panorama da educação em enfermagem no Brasil. In: Anais do Seminário Nacional de Pesquisa em Enfermagem. Rio Grande do Norte: Associação Brasileira de Enfermagem; 2013.

6. Teixeira E, Vale EG. Tendências e perspectivas do ensino de graduação em enfermagem. In: Teixeira E, Vale EG, Fernandes JD, Sordi MRL (orgs). 0 ensino de graduação em enfermagem no Brasil: 0 ontem, o hoje e 0 amanhã. Brasília: Instituto Nacional de Estudos e Pesquisas Educacionais Anísio Teixeira; 2006. 244p. 
7. Toso BR. Práticas avançadas de enfermagem em atenção primária: estratégias para implantação no Brasil. Enferm Foco. 2016;7(3/4),36-40.

8. Ministério da Educação [Internet]. e-MEC. 2017 [cited 2017 Mar 10]. Available from: http://portal.mec.gov.br/e-mec-sp-257584288.

9. Sociedade Brasileira de Enfermeiros Pediatras (SOBEP). Institucional: quem somos [acesso em 20 Apr 2020]. Disponível em: https://sobep.org.br/institucional/quem-somos/

10. Machado MH, Wermelinger M, Vieira M, Oliveira E, Lemos W, Aguiar Filho W, et al. Aspectos gerais da formação da enfermagem: 0 perfil da formação dos enfermeiros, técnicos e auxiliares. Enferm Foco 2016;6(2/4):15-34.

11. França T, Magnago C. Políticas, programas e ações de educação na saúde: perspectivas e desafios. Saúde Debate. 2019;43(n. especial 1) 4-11.

12. Oliveira MC, Lima TL, Baluta VH. A formação do profissional enfermeiro, no contexto das reformas de ensino no Brasil. Grifos. 2014;36(37):161-86.

13. Vieira AL, Moyses NM. Trajetória da graduação das catorze profissões de saúde no Brasil. Saúde Debate. 2017;41(113):401-14.

14. Silva V0, Pinto ICM. Produção científica sobre docência em saúde no Brasil. Saúde Debate. 2019;43(n. especial 1):134-47.

15. Fernandes JD, Silva RM, Silva AC, Mota LS, Cordeiro AL, Souza RS. Perfil dos cursos de especialização em enfermagem no município de Salvador, Bahia, Brasil. Rev Baiana Enferm. 2017;31(2):e16660.
16. Brasil. Ministério da Saúde. Secretaria de Gestão do Trabalho e da Educação na Saúde. Departamento de Gestão da Educação na Saúde. Política Nacional de Educação Permanente em Saúde: 0 que se tem produzido para 0 seu fortalecimento? Brasília (DF): Ministério da Saúde; 2018.

17. Martins FR, Morini MS, Olinda AG, Barros FH, Silva LO, Roseno MA. Necessidades de qualificação do processo de trabalho da Enfermagem em UTI Pediátrica. Id on Line Rev Mult Psic. 2019;13(43):322-28.

18. Santos FC, Camelo SH. 0 enfermeiro que atua em unidades de terapia intensiva: perfil e capacitação profissional. Cultura de los Cuidados. 2015;19(43):127-40.

19. Alfieri E, Alebbi A, Bedini MG, Boni L, Foà C. Mapping the nursing competences in neonatology: a qualitative research. Acta Biomed. 2017;88(3S):51-8.

20. Magnabosco G, Haddad MC, Vannuchi MT, Rossaneis MA, Silva LG. Opinião de egressos sobre 0 curso de residência em gerência dos serviços de enfermagem. Semina Cienc Biol Saude. 2015;36(Supl):73-80.

21. Silva RM, Freitas LS, Araújo CL, Camargo JH, Franco AM, Silva JN, et al. Importância da residência em enfermagem no processo ensino-aprendizagem: uma revisão integrativa. Rev Enferm Atual In Derme, 2018;86(Ed. Esp):1-14.

22. Silva RM, Luz MD, Fernandes JD, Silva LS, Cordeiro AL, Mota LS. Tornar-se especialista: expectativas dos enfermeiros portugueses após a realização do curso de especialização. Rev Enf Ref. 2018;16(4):147-54. 